\title{
Modification to single catheter exchange transfusion technique
}

\author{
J. H. TRIPP and T. VALAES
}

From the Rhesus Unit, Lewisham Hospital, London, and Aghia Sophia Children's Hospital, Athens

\begin{abstract}
Tripp, J. H., and Valaes, T. (1976). Archives of Disease in Childhood, 51, 293. Modification to single catheter exchange transfusion technique. A simple modification to the standard 'in-out' exchange transfusion technique is described which requires cannulation of the umbilical vein only, yet provides many of the theoretical and practical advantages of a 2-catheter arteriovenous technique. The advantages include a reduction of cardiovascular disturbance; a reduction of the inevitable pressure changes in the portal venous system (probably important in the pathogenesis of complicating necrotizing enterocolitis); administration of alkali or drugs diluted in donor blood; accurate assessment of balance; a more efficient exchange; and general ease of management allowing better clinical observation of the infant.
\end{abstract}

Exchange transfusion of neonates in the U.K. is commonly performed via a single umbilical vein catheter. Other methods have been suggested, notably the 2-catheter arteriovenous, continuous exchange currently used in the Lewisham unit (Ata and Holman, 1966; Gairdner, 1966). Continuous exchange by this route has many theoretical and practical advantages but arterial catheterization is not always possible and may, rarely, cause complications (Gupta, Roberton, and Wigglesworth, 1968; Qureshi and Puri, 1971). Difficulty in performing the arterial catheterization is related directly to the age of the neonate and inversely to the experience and expertise of the operator. The latter factors were also found to be related to the incidence of complications, as was the experience of the procedure in the unit as a whole (Gupta et al., 1968). At least one large unit has decided on these grounds that a single catheter technique is preferable (Walker, 1971). In smaller units where fewer arterial catheterizations are done, and the risks and difficulties thereby increased, a single catheter technique may be more practical. The modification described below combines certain of the advantages of the continuous arteriovenous technique, with a lack of possible difficulty or complication and is suitable for general adoption.

Received 8 August 1975.

\section{Methods}

The following materials were used. The usual sterile instruments for performing umbilical vein catheterization; two 3-way disposable taps (e.g. Pharmaseal Laboratories); (in the text these taps are described as 'closed' to one or other arm, the other 2 arms then being connected to each other; for the alternative modification described below, a single 4-way tap may be modified by the manufacturers as described (Valaes, 1966)); umbilical catheter (e.g. Warne 6FG umbilical feeding tube); syringe, 10 or $20 \mathrm{ml}$; drip extension tube (sterile); intravenous giving set with filter and $100 \mathrm{ml}$ graduated reservoir; glass measuring cylinder graduated in $10 \mathrm{ml}$ divisions to $250 \mathrm{ml}$, with or without drainage outlet of wide bore at the bottom.

The Fig. gives details. A tap is attached to the umbilical catheter (tap 1), the tap and the catheter filled with heparinized saline (10 units $/ \mathrm{ml}$ ), and the tap closed to the catheter. The cord is cut about $1 \mathrm{~cm}$ from the abdomen and the umbilical vein aseptically cannulated. The particular catheter used is very flexible and soft causing the minimum damage to the vein. It is packed in an inner sterile bag enabling a 'no touch' technique to be used in addition to 'glove mask, and gown'. It is also marked in inches to ensure that it is inserted to the correct distance. To the side of this tap the infusion set primed with donor blood is attached. To the second arm of the tap, another tap ( $\operatorname{tap} 2$ ) is attached in line with the drip extension tube leading to the waste measuring cyclinder. To the remaining arm the syringe is to be attached. The second tap and extension tubes are filled with heparinized saline and then closed to waste. 


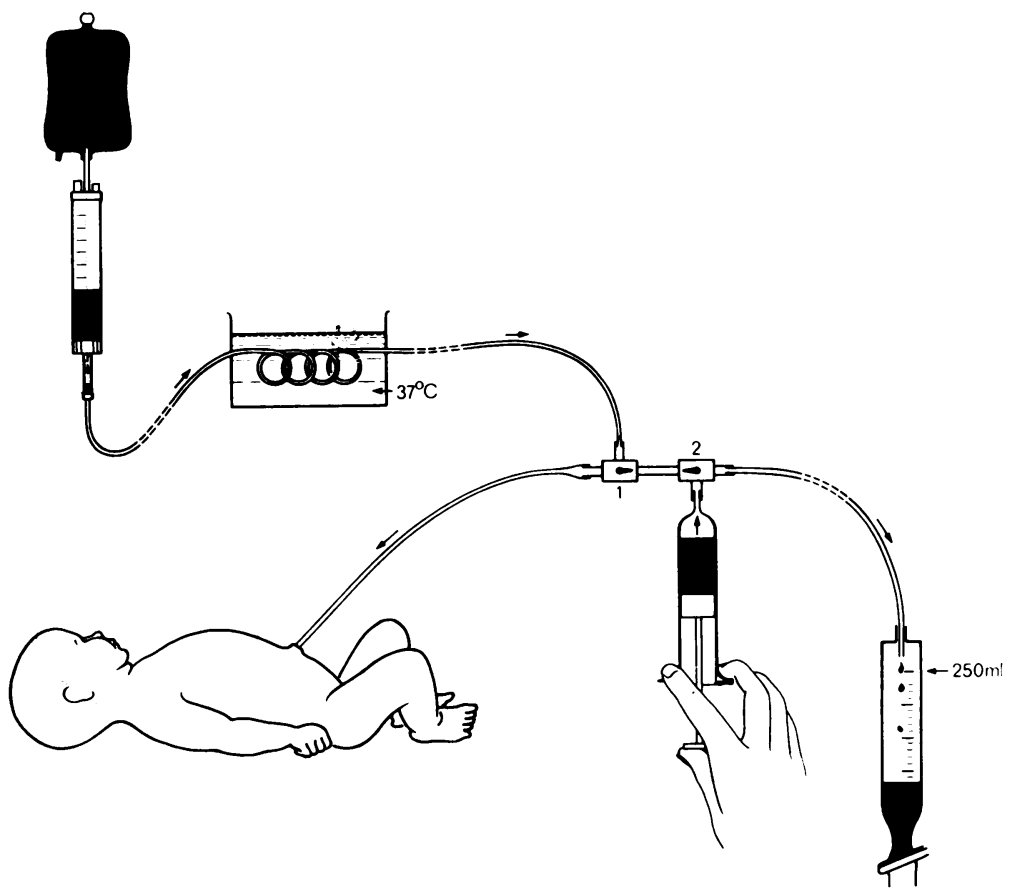

FIG.-Modified exchange transfusion system.

(This prevents clotting and fills up this tube so that measurements in the cylinder reflect the actual volume of blood removed from the infant.) A $10 \mathrm{ml}$ syringe is then attached $(20 \mathrm{ml}$ if it is a fit baby of more than 2.5 $\mathrm{kg}$ ) to the side of tap 2, tap 1 is closed to the infusion set (i.e. syringe and neonate are now connected), and blood withdrawn into the syringe. Tap 1 is now closed to tap 2 and the infusion run at about $5 \mathrm{ml} / \mathrm{min}$. While this is being run in tap 2 is turned to empty syringe to waste and then closed again to waste. During this infusion period observation of the infant can also be made, and when $10 \mathrm{ml}$ has been run in from the reservoir tap 1 is closed to the infusion set and the cycle repeated.

Alternative modification. The method previously described (Valaes, 1960, 1966) uses a modified 4-way tap allowing blood to drip through a narrow alternative channel on the outside of the tap piston while the tap is in the 'syringe to waste' position. The method is otherwise identical and the advantages the same.

\section{Discussion}

Effects of infusion of blood on cardiovascular system. Ata and Holman (1966) felt that one of the main dangers inherent in the 'push-pull' technique (Walker and Neligan, 1955; Diamond, Allen, and Thomas, 1951) was associated with the possibility of too rapid injection of blood from the syringe, particularly likely to occur at the end of the stroke with the last 2 or $3 \mathrm{ml}$. They suggested that at this time there was an unacceptable strain put on the heart, and collapse of the infant occasionally ensued. (Those of us who regularly use the push-pull technique are well aware of the temptation and the danger of pushing in the last $2 \mathrm{ml}$ or so in order to get on to the next cycle, particularly if the withdrawal phase is not easy and the cycle delayed.) Cropp (1967) and Gairdner (1966) also suggested that the push-pull method was frequently associated with excessive strain on the cardiovascular system and they also came to the conclusion that a continuous arteriovenous exchange would be more acceptable.

Effects on portal venous circulation. Necrotizing enterocolitis is one of the serious complications of exchange transfusion via the umbilical vein (Castor, 1968; Friedman et al., 1970), with an incidence of symptoms of the condition in as many as $1.4 \%$ in a series of 142 infants observed by Touloukian, Kadar, and Spencer (1973). These workers conducted a series of experiments in piglets using a standard push-pull technique and showed that there are significant and rapid changes in the 
portal venous pressure and some compromising of colonic blood flow during certain stages of the procedure. They suggest that the rapid changes in pressure may initiate vasospasm in the portal system and further reduce intestinal blood flow. Kobayashi et al. (1975) suggest that haemodynamic changes in the portal system may cause vessel damage resulting in portal venous thrombosis and hypertension.

Using the standard method and hopefully adhering to the maxim ' 1 minute out, 2 minutes in', only $50 \%$ of the cycle at best is available for injection when allowance is made for filling and emptying the syringe and turning both taps twice in each cycle. Using the simple modification described, the blood is infused by gravity at a constant controlled rate and pressure and $75 \%$ of the cycle is available for infusion.

Addition of bicarbonate. Gandy, Partridge, and Gairdner (1968) concluded that sodium bicarbonate should be added to donor acid citrate and dextrose (ACD) blood when exchanges are performed on the first day of life and obviously also in infants with an element of acidosis due to respiratory distress. Addition of bicarbonate, which is now standard practice, is facilitated by adding it to the reservoir via the injection rubber provided. It is then given diluted with donor blood and not in a concentrated, high osmolarity bolus into the vein which may itself predispose to endothelial damage and portal vein thrombosis (Scott, 1965; Erkan, Blankenship, and Stahlman, 1968).

Blood balance. Using the push-pull technique the net balance of blood in and out is maintained by adhering rigidly to a set order of actions. It is notoriously easy, particularly if the infant is sick and needs other attention, to be uncertain exactly which stage of the cycle has been reached, jeopardizing the final balance. Using the suggested modification there are two advantages. Firstly, blood in the syringe is always that of the infant, never donor, and is thus always emptied to waste so that there can be no error. Secondly, if the exchange is halted in an emergency the exact totals 'in' and 'out' can be immediately ascertained from the level in the drip reservoir, and waste measuring cylinder.

Dead space and efficiency of exchange. The efficiency of an exchange can be assessed by calculating the percentage of fetal blood remaining in the infant's circulation at the end of the exchange
(Wallerstein and Brodie, 1948). An important factor in determination of the efficiency is the dead space between the tip of the catheter and syringe plunger composed of the lumen of the catheter, taps, and the syringe butt. Using the suggested modification this dead space is reduced by the volume in one complete tap and the syringe butt. Using our equipment, which is of minimal volume, this is a saving of 0.4 out of a total of $0.8 \mathrm{ml}$.

In conclusion, we have found this modification to the single catheter technique makes the procedure less tiring, less open to error, and enables a better monitoring of the infant's general condition. The same technique has been extensively used by workers in Greece (Panagopoulos, Valaes, and Doxiadis, 1969). We suggest it is the method of choice for exchange transfusion, at least in units where a single catheter technique is favoured.

J. H. T. thanks Dr. C. A. Holman for help in the the development of the method, and Dr. R. J. K. Brown for constructive criticism.

\section{REFERENCES}

Ata, M., and Holman, C. A. (1966). Simultaneous umbilical arteriovenous exchange transfusion. British Medical fournal, 2, 743.

Castor, W. R. (1968). Spontaneous perforation of the bowel in the newborn following exchange transfusion. Canadian Medical Association Fournal, 99, 934.

Cropp, G. J. A. (1967). Experience with a new isovolumetric exchange transfusion method. Fournal of Pediatrics, 71, 332.

Diamond, L. K., Allen, F. H., and Thomas, W. O. (1951). Erythroblastosis fetalis: treatment with exchange transfusion. New England fournal of Medicine, 244, 39.

Erkan, V., Blankenship, W., and Stahlman, M. T. (1968). The complications of chronic umbilical vessel catheterisation. Pediatric Research, 2, 317.

Friedman, A. B., Abellera, R. M., Lidsky, I., and Lubert, M. (1970). Perforation of the colon after exchange transfusion in the newborn. New England fournal of Medicine, 282, 796.

Gairdner, D. (1966). Exchange-transfusion techniques. Lancet, $2,545$.

Gandy, G., Partridge, J. W., and Gairdner, D. (1968). Control of acidosis during exchange transfusion with citrated blood. Archives of Disease in Childhood, 43, 147.

Gupta, J. M., Roberton, J. R. C., and Wigglesworth, J. S. (1968). Umbilical artery catheterization in the newborn. Archives of Disease in Childhood, 43, 382.

Kobayashi, Y., Akaishi, K., Nishio, T., Kobayashi, Y., and Maetani, S. (1975). Portal hypertension following exchange blood transfusion with complications of Listeria meningitis. Zeitschrift für Kinderheilkunde, 119, 105.

Panagopoulos, G., Valaes, T., and Doxiadis, S. A. (1969). Morbidity and mortality related to exchange transfusions. Fournal of Pediatrics, 74, 247.

Qureshi, M. E., and Puri, S. P. (1971). Osteomyelitis after exchange transfusion. British Medical fournal, 2, 28.

Scott, J. M. (1965). Iatrogenic lesions in babies following umbilical vein catheterization. Archives of Disease in Childhood, 40, 426. 
Touloukian, R. J., Kadar, A, and Spencer, R. P. (1973). The gastrointestinal complications of neonatal umbilical venous exchange transfusion. A clinical and experimental study. Pediatrics, 51, 36.

Valaes, T. (1960). Drip method for exchange transfusion. Lancet, $2,496$.

Valaes, T. (1966). Exchange-transfusion apparatus. Lancet, $1,1215$.

Walker, W. (1971). Recent Advances in Paediatrics, 4th ed., p. 119. Ed. by D. Gairdner and D. Hull. Churchill, London.
Walker, W., and Neligan, G. A. (1955). Exchange transfusion in haemolytic disease of the newborn. British Medical fournal, 1,681 .

Wallerstein, H. and Brodie, S. S. (1948). Efficiency of blood substitutution. American fournal of Clinical Pathology, 18, 857.

Correspondence to Dr. J. H. Tripp, Institute of Child Health, 30 Guilford Street, London WC1N 1EH.

The following articles will appear in future issues of this journal:

Tinidazole in treatment of acute amoebic dysentery in children. J. N. Scragg, C. J. Rubidge, and E. M. Proctor.

Clinical evaluation of tinidazole in amoebiasis in children. T. Ahmed, F. Ali, and S. G. Sarwar.

Serum immunoglobulins in multiple pregnancy. E. Bryan, B. Slavin, and E. Nicholson.

Congenital nephrotic syndrome of Finnish type: study of 75 patients. N.- P. Huttunen.

Chloride losing diarrhoea and metabolic alkalosis in an infant with cystic fibrosis. H. I. Hochman, N. R. Fiens, R. Rubin, and J. Gould.

Immunogloblin $\mathrm{E}$ in erythema nodosum. C. Mandalenaki-Asfi, Th. Thomaidis, S. Benetos, B. Ladis, and N. Matsaniotis. 